\title{
La imagen del protocolo a través de la prensa española
}

\author{
Elena BORAU BOIRA \\ Universidad Complutense de Madrid \\ eborau@gmail.com
}

Recibido: 20/10/2012

Aceptado: 23/01/2013

\section{Resumen}

El tratamiento informativo que los medios hacen de un terma en concreto, es determinante a la hora de influir en la percepción que la sociedad puede tener a cerca del mismo. Por ello, en el presente estudio se analizará cómo es el tratamiento informativo que la prensa española hace del protocolo, ya que se parte de la premisa de que ocupa escasa relevancia en la prensa española, lo que influye en el desconocimiento que la sociedad tiene del mismo.

Palabras clave: Protocolo, Medios de Comunicación, Prensa, Opinión Pública, Tratamiento Informativo.

\section{The Protocol's Image Through the Spanish Press}

\begin{abstract}
The informative treatment that mass media makes about a specific subject, has determinant influence in the perception that the society has about it. That is way, in the present article will be analyzed how is the informative treatment that Spanish press make about the protocol. Because it comes from the point of Press confers barely importance, which seriously influences on the ignorance that our society has about protocol.

Keywords: Protocol, Mass Media, Press, Public Opinion, Informative Treatment.

\section{Referencia normalizada}

BORAU BOIRA, Elena (2013): "La imagen del protocolo a través de la prensa española". Estudios sobre el mensaje periodístico. Vol. 19, Núm. especial abril, págs.: 633-639. Madrid, Servicio de Publicaciones de la Universidad Complutense.
\end{abstract}

Sumario: 1. Introducción. 2. Metodología; 2.1. Hipótesis; 2.2. Procedimientos. 3. Desarrollo; 3.1. Muestra y unidad de análisis; 3.2. Libro de códigos; 3.3. Resultados. 4. Conclusiones. 5 Referencias bibliográficas

\section{Introducción}

Los medios contribuyen a la formación de la opinión pública de manera sutil, indirecta y a largo o medio plazo. La prensa juega un papel fundamental en la configuración de la cultura de la sociedad, por lo que también es determinante en cuanto a la creación de la percepción social del protocolo. Van Dijk (2008: 278) afirma que los medios de comunicación son las instituciones que juegan el papel más preponderante en la reproducción de las representaciones sociales interculturales, "los medios son actualmente la fuente más influyente de tendencias racistas, prejuicios y racismo". En esta línea, Vinuesa (2008: 267) apunta: "los medios son vistos como instrumentos de creación de opinión, de opinión pública".

Por este motivo, la principal fuente de referencia para llevar a cabo esta investigación son los medios de comunicación y más concretamente la prensa, porque es el fiel reflejo de nuestra sociedad y permite la visibilización de la realidad que vivimos. La información pública o de interés general es relevante y se sustenta en los medios de comunicación social que, según Aguado (2004: 258) "producen, transforman, re- 
producen y distribuyen conocimiento a través de informaciones, productos culturales y de entretenimiento, destinados a crear opinión o a promover el consumo".

Las imágenes y los encuadres visuales que contienen desarrollan un papel importante dentro de los contenidos noticiosos, pues acompañan a los textos aportando datos adicionales que refuerzan la información referida al tema sobre el que se ha dado cobertura en la noticia. Estos datos ponen de manifiesto que la cobertura informativa sobre temas como el protocolo, puede constituir un factor explicativo de la percepción que la sociedad tiene de ella, el reconocimiento y la importancia que le confiere en la actualidad.

En el proyecto metodológico propuesto, todos los HECHOS que se va a analizar son Noticias, que según la Real Academia Española (RAE) ${ }^{1}$ se definen como hechos novedosos ocurridos dentro de una comunidad o determinado ámbito especifico, que hace que merezcan su divulgación. Pero, ¿qué entendemos realmente por noticia?

A medio camino entre la teoría y la práctica, se encuentra la definición de Ortego (1996: 48), "todo acontecimiento actual, interesante y comunicable". En la misma línea, De Gregorio (1966: 99) afirma que "es la narración en la forma más objetiva posible de un hecho verdadero, inédito y de interés general". Pero posiblemente, la definición más amplia y ajustada sea la que nos ofrece Martínez Albertos (1972: 37), "noticia es un hecho verdadero, inédito o actual, de interés general, que se comunica a un público masivo, una vez recogido, interpretado y valorado por quienes controlan el medio utilizado para su difusión".

En resumen, y atendiendo a las peculiaridades que recogen la mayoría de los teóricos, se puede concluir que noticia es todo hecho importante, interesante, nuevo y verdadero que la gente necesita conocer. Este mismo criterio, por tanto, es el que se ha aplicado para recopilar las noticias que posteriormente se analizarán.

Sobre este escenario, fundamentado en la realidad, es sobre el que se basa la presente investigación, cuyo principal objetivo es su verificación empírica a través de un análisis de contenido en el que se determinará el tratamiento informativo que la prensa española hace de esta disciplina, partiendo siempre de la premisa de que le confiere escasa importancia al protocolo.

\section{Metodología}

\subsection{Hipótesis}

A continuación se definen las principales hipótesis del presente estudio como explicaciones tentativas del fenómeno investigado, y que se intentarán verificar a lo largo de la investigación.

- H1: El protocolo, en su acepción "protocolo-ceremonial", tiene poca presencia en la prensa española.

- H2: En las noticias protocolarias predominan los encuadres noticiosos que otorgan una menor relevancia a la información.

- H3: El tratamiento informativo que la prensa hace del protocolo influye en su escaso reconocimiento social.

1 Real Academia Española: http://lema.rae.es/drae/?val=noticia. (Consultado el 19-11-11) 


\subsection{Procedimientos}

A partir de la técnica de investigación llamada "análisis de contenido", crearemos un modelo "ad hoc", donde a partir de los datos recabados, se formularán unas inferencias reproducibles y válidas, que se podrá aplicar al contexto global, y que comprende la sociedad actual.

Por motivos de espacio, sólo se expondrá la definición de análisis de contenido que realiza Bardin (1996: 32) ya que engloba diferentes perspectivas y resulta más completa para nuestro campo de estudio:

"Conjunto de técnicas de análisis de las comunicaciones tendentes a obtener indicadores, cuantitativos o no, por procedimientos sistémicos y objetivos de descripción del contenido de los mensajes".

Asimismo, la investigación se fundamentará en los desarrollos recientes de la perspectiva de la Agenda Setting y la Teoría del Framing, que plantean que los contenidos informativos no sólo fijan la agenda pública, sino que también dictan implícitamente al público una forma de pensar sobre ciertos asuntos. (Igartua y Humanes, 2004). En este contexto, tiene una especial relevancia teórica el análisis de contenido con el que se analizará el tratamiento informativo que la prensa hace del protocolo y en último término, la relevancia que ésta le concede.

\section{Desarrollo}

\subsection{Muestra y unidad de análisis}

Se seleccionará los tres periódicos más importantes de pago y de tirada nacional del país según la Oficina de Justificación de la Difusión y el Estudio General de Medios (OJD y EGM) ${ }^{2}$ : El País, El Mundo y $A B C$, que representan la referencia informativa de nuestro país y por lo tanto son fiables indicadores y extrapolables a la prensa escrita en general; Se elegirá la versión impresa sobre la versión on line; El corpus resultante estará formado por las noticias publicadas por estos tres periódicos del 1 de enero de 2010 al 31 de diciembre de 2010, en las que aparezca el concepto "protocoloceremonial".

\subsection{Libro de códigos}

La importancia y el emplazamiento del protocolo en la prensa española se medirá a través de unos indicadores que permiten comprobar el encuadre, el énfasis mediático y en definitiva, la relevancia que ésta otorga al objeto de estudio. La clasificación "ad hoc" que se ha creado es la siguiente:

Presencia/ausencia del concepto protocolo en la muestra total analizada; Representación del término protocolo en portada; Autor con más presencia firmando noticias sobre protocolo (redactor nacional, enviado especial, corresponsal, redacción periódico, colaborador, columnista, editorial, transcripción agencia o cartas al director); Presencia de noticias sobre protocolo acompañadas de fotografías; Frecuencia

2 Página web de Estudio General de Medios: http://www.aimc.es/-Datos-EGM-Resumen-General-.html. Abril 2010 - marzo 2011. (Consultado 28-12-11). 
de elementos gráficos en las noticias protocolarias; Tamaño de la noticia protocolaria (más de una página, página completa o parte de página); Presencia de noticias protocolarias en contraportada; Presencia de protocolo en el titular; Porcentaje de noticias protocolarias que abren la sección; Sección en donde más presencia tiene el protocolo (agenda, contraportada, cultura, deportes, economía, nacional, internacional, Madrid, obituarios, opinión, portada, sociedad).

Estos indicadores, junto con las teorías de expertos recabadas en la introducción, serán las que permitan refutar -o no- las hipótesis anteriormente planteadas.

\subsection{Resultados}

» Presencia/Ausencia de protocolo en la muestra seleccionada:

La muestra total de noticias la componen 90.447 unidades de análisis, corpus suficientemente amplio como para obtener unos resultados solventes y contrastables. El recuento de datos por periódicos es el siguiente:

$A B C$ : De 31.718 unidades de análisis que componen la muestra total, 87 contienen el concepto "protocolo-ceremonial", es decir, el 0,3\% del total de la muestra.

El Mundo: De 31.790 unidades de análisis, en 141 aparece el término protocolo, es decir el $0,4 \%$ del total.

El País: De 26.934 que componen la muestra, 81 contienen el concepto protocolo, lo que equivale al $0,3 \%$ del corpus total.

» Presencia de protocolo en la portada:

Del total de la muestra analizada, sólo una noticia que versa sobre protocolo en $A B C$ y en El País va en portada, es decir un 1,1\% y un 1,2\% del total respectivamente. En El Mundo aparecen dos noticias, con lo que la presencia sube al 1,4\% del total.

» Tipo de autor que más a menudo firma las noticias sobre protocolo:

En $A B C$ el redactor nacional tiene un $39,1 \%$ de presencia y el columnista un $18,4 \%$ del total. En El Mundo el redactor nacional tiene un 60,3\% y el columnista un $10,6 \%$ del total. En El País, el redactor nacional firma un 67,9\% y el columnista un $9,9 \%$ del total.

» Presencia de fotografías en noticias protocolarias:

$A B C$ es la cabecera con mayor presencia tiene en la categoría de noticias sobre protocolo que van acompañadas de fotografía con un 79,3\% seguido de El País con un 75,3\% y El Mundo con un 71,6\% del total.

» Presencia/Ausencia de elementos gráficos ilustrando noticias que contienen protocolo:

El Mundo y El País tienen una misma presencia coincidiendo con un 9,9\%, seguido de $A B C$, con un $2,3 \%$ respecto del total. 
» Tamaño más frecuente para las noticias sobre protocolo:

El porcentaje más alto es para las noticias que ocupan menos de una página en todos los periódicos, en $A B C$ con un $62,1 \%$ del total, en El Mundo con un 52,5\% y en El País con un 64,2\%.

» Presencia de protocolo en contraportada:

El País es el que mayor presencia tiene de protocolo en contraportada con un 2,5\%, le sigue $E l$ Mundo con un 2,1\% y por último está $A B C$ con una presencia de protocolo nula $(0 \%)$ en contraportada.

» Presencia de protocolo en el titular:

El Mundo es el periódico que más presencia tiene de protocolo en el titular con un $5 \%$, siguiéndole El País con un $1,2 \%$ y por último $A B C$ con un $1,1 \%$ del total.

» Presencia de noticias sobre protocolo que abren la sección:

El Mundo es la cabecera con una mayor presencia de protocolo en las noticias que abren la sección con un $18 \%$, le sigue El País con $16,5 \%$ y después $A B C$ con un $8,1 \%$ del total de la muestra.

\section{4 .Conclusiones}

Se procederá a la verificación de las tres hipótesis planteadas:

- Hipótesis 1: El protocolo, en su acepción "protocolo-ceremonial", tiene poca presencia en la prensa española.

Efectivamente, a través de la investigación, se comprueba que la acepción "protocolo-ceremonial" tiene una presencia realmente escasa en la prensa española con un $0,3 \%$ en El País y en $A B C$ y un $0,4 \%$ el total en El Mundo.

Resaltar que la Agenda Setting ha sido fundamental para entender el comportamiento y editorial de los medios y por lo tanto también nuestro estudio. Desde que aparecieron los medios de comunicación, los individuos hemos delegado nuestra percepción de aquello que no podemos abarcar en estos poseedores de la información. Los procesos de selección de esta información se convierten en filtros de la realidad. Es evidente que hace falta seleccionar al haber una sobreabundancia de información pero, al hacer una selección, el medio toma partido al priorizar. Por tanto, y si se tiene en cuenta que de una muestra compuesta por 90.447 noticias, sólo 309 contienen el término "protocolo-ceremonial", la única conclusión que podemos extraer es que nuestro objeto de estudio pasa casi desapercibido en la prensa española y por consiguiente, influye en el hecho de que la sociedad lo perciba como algo secundario $\mathrm{y}$ de poca importancia.

- Hipótesis 2: En las noticias protocolarias predominan los encuadres noticiosos que otorgan una menor relevancia a la información.

La investigación ha evidenciado que las noticias que versan sobre protocolo y los encuadres que ocupan en la prensa española son indicativos de la escasa relevancia que ésta le concede. De las nueve variables que se han empleado para medir la relevancia informativa del protocolo, siete muestran la escasa presencia que el protocolo ocupa 
en posiciones relevantes en cuanto a la jerarquización de la información. La casi nula presencia de protocolo en la portada de los tres periódicos, el ínfimo acompañamiento de protocolo con elementos gráficos, el tamaño de las noticias protocolarias cuya mayoría absoluta ocupa siempre menos de una página en las tres cabeceras, la escasa presencia de protocolo en contraportada, la baja representación del término protocolo en el titular o la leve frecuencia con la que las noticias protocolarias abren la sección, corroboran claramente esta hipótesis.

En variable está fundamentad en la Teoría del Framing, ya que, además de seleccionar, también se jerarquizan las noticias seleccionadas, informando implícitamente a la audiencia acerca de la relevancia de la información. Decide cuál será el foco principal de la historia e implica encuadrar los hechos utilizando un enfoque determinado. Un elemento de esta nueva aproximación a la comunicación de masas es el descubrimiento de que la audiencia no se entera únicamente de los hechos por medio de su exposición a los medios informativos sino que también conoce la importancia de los temas tratados en las noticias, según el énfasis que le den los medios. Por lo tanto, y después de comprobar que de las nueve variables que miden la jerarquización de contenidos dentro de un periódico, siete indican escasa relevancia a los temas protocolarios, se puede concluir que el tratamiento informativo que la prensa hace de nuestro objeto de estudio le otorga ínfima importancia, lo que puede ser determinante para que la sociedad también lo relegue a un segundo plano.

- Hipótesis 3: El tratamiento informativo que la prensa hace del protocolo influye en el escaso reconocimiento social del protocolo.

Después de comprobar la escasísima presencia que el protocolo tiene en la prensa española, la poca relevancia que le confiere según el tratamiento informativo que lleva a cabo, y la demostración a través de numerosas teorías de que los medios influyen en la percepción social de un tema determinado, se puede dar por confirmada la hipótesis principal: el tratamiento informativo que la prensa hace del protocolo influye en su escaso reconocimiento social.

Teorías y conceptos en los que se ha basado este modesto pero no menos riguroso análisis y con el que se ha comprobado lo que supone una reivindicación constante en el sector profesional del protocolo, pero que todavía no se había determinado con rigor metodológico: la escasa importancia que la prensa otorga a la acepción "protocolo-ceremonial" y la correspondiente influencia que ésta ejerce en la sociedad.

\section{Referencias bibliográficas}

AGUADO, Miguel Ángel (2004): Introducción a las teorías de la comunicación y la información. Murcia, Editorial ICE D.M.

BARDIN, Laurence (2002): El Análisis de Contenido. Madrid, Akal.

DE GREGORIO, Domenico (1966): Metodología del Periodismo. Madrid, Ediciones Rialp.

ESTUDIO GENERAL DE MEDIOS (EGM): http://www.aimc.es/-Datos-EGM-Resumen-General-.html. Abril 2010 - marzo 2011. [Consultado 28-12-11] 
IGARTUA, Juan José y HUMANES, María Luisa (2004): Teoría e investigación en comunicación social. Madrid, Síntesis.

MARTÍNEZ ALBERTOS, José Luis (1972): La Información de una sociedad industrial. Madrid, Tecnos.

ORTEGO, José (1996): Noticia, Actualidad, Información. Pamplona, Instituto de Periodismo. Pamplona.

REAL ACADEMIA ESPAÑOLA: www.rae.es: http://lema.rae.es/drae/?val=protocolo. Tercera acepción [Consultado el 10-09-11].

VAN DIJK, Teun (2008): Reproduciendo el racismo: El rol del racismo. Barcelona, Gedisa.

VINUESA, María Lourdes (2008): “La opinión pública medida y mediatizada. La comunicación social en la España democrática”. Estudios sobre el mensaje periodístico. Vol 14. Madrid. Servicio de Publicaciones de la Editorial Complutense, pp. 267-289.

\section{Elena BORAU BOIRA}

Doctora por la Universidad Complutense de Madrid con la tesis "Protocolo y diplomacia a través de la prensa española". Licenciada en Ciencias de la Información por la Universidad Complutense de Madrid. Posgrado en Fordham University (NYC) sobre redacción periodística. Máster en Protocolo y Relaciones Internacionales por la Universidad Camilo José Cela. Durante más de siete años ha trabajado como Responsable de Prensa en diferentes gabinetes de comunicación. Actualmente es la Responsable de Comunicación de la Asociación Española de Protocolo

eborau@gmail.com 